\title{
Construção de Fanpage para o SAMU-CE: uma ferramenta de comunicação
}

\section{institucional}

\author{
Fanpage construction for SAMU-CE: an institutional communication tool \\ Construcción de fanpage para SAMU-CE: una herramienta de comunicación institucional
}

Recebido: 13/12/2021 | Revisado: 17/12/2021 | Aceito: 21/12/2021 | Publicado: 03/01/2022

\author{
Rillma Marques Melo Nunes \\ ORCID: https://orcid.org/0000-0003-1954-668X \\ Universidade Estadual do Ceará, Brasil \\ E-mail: rillmamelo@gmail.com \\ Dina Mara Formiga da Silva \\ ORCID: https://orcid.org/0000-0002-5387-7194 \\ Universidade Estadual do Ceará, Brasi \\ E-mail: dinamara_silva@hotmail.com \\ Maria Salete Bessa Jorge \\ ORCID: https://orcid.org/0000-0001-6461-3015 \\ Universidade Estadual do Ceará, Brasil \\ E-mail: maria.salete.jorge@gmail.com
}

\begin{abstract}
Resumo
Objetivo: Construir uma ferramenta de comunicação institucional uma ferramenta de gestão poderosa que, sendo estrategicamente utilizada, pode agir de forma a interiorizar as metas, os valores, a missão e a visão da instituição. Metodologia: Trata-se de um estudo de desenvolvimento metodológico realizada com os trabalhadores do SAMU 192 Ceará. A construção desta ferramenta ocorreu pela busca na literatura científica através de uma revisão integrativa. Também se utilizou a aplicação de um questionário com característica sociodemográfica. Em seguida houve a validação de conteúdo da ferramenta com especialistas e validação de usabilidade com os trabalhadores do SAMU 192 Ceará. Resultados e Discussão: A referida ferramenta passou pela validação de juízes/especialistas, a mesmo apresentou IVC significativo (0,88 valor superior ao mínimo necessário), bem como pontuação SUS (maior do que 70, neste caso 71,5) revelando a aplicabilidade da fanpage junto aos trabalhadores do SAMU 192 CE. Conclusão: Espera-se que a presente ferramenta possa auxiliar na melhoria da comunicação, promovendo uma maior integração entre os gestores e trabalhadores e favorecer a difusão e a interiorização das metas e valores, bem como da missão e da visão da instituição.
\end{abstract}

Palavras-chave: Comunicação; Fanpage; Publicidade; SAMU.

\begin{abstract}
Objective: To build an institutional communication tool a powerful management tool that, being strategically used, can act in a way that internalizes the goals, values, mission and vision of the institution. Methodology: This is a methodological development study conducted with the workers of SAMU 192 Ceará. The construction of this tool occurred through the search in the scientific literature through an integrative review. The application of a questionnaire with sociodemographic characteristic was also used. Then there was the validation of the content of the tool with specialists and usability validation with the workers of SAMU 192 Ceará. Results and Discussion: This tool passed through the validation of judges/specialists, and it presented significant CVI (0.88 value higher than the minimum required), as well as SUS score (higher than 70, in this case 71.5) revealing the applicability of fanpage to the workers of samu $192 \mathrm{CE}$. Conclusion: It is expected that this tool can help improve communication, promoting greater integration between managers and workers and favor the dissemination and internalization of goals and values, as well as the mission and vision of the institution.
\end{abstract}

Keywords: Communication; Fanpage; Advertising; SAMU.

\section{Resumen}

Objetivo: Construir una herramienta de comunicación institucional una poderosa herramienta de gestión que, al ser utilizada estratégicamente, pueda actuar de manera que se interioricen las metas, valores, misión y visión de la institución. Metodología: Este es un estudio de desarrollo metodológico realizado con los trabajadores de SAMU 192 Ceará. La construcción de esta herramienta se produjo a través de la búsqueda en la literatura científica a través de una revisión integradora. También se utilizó la aplicación de un cuestionario con característica sociodemográfica. Luego estuvo la validación del contenido de la herramienta con especialistas y la validación de usabilidad con los trabajadores de SAMU 192 Ceará. Resultados y Discusión: Esta herramienta pasó por la validación de 
jueces/especialistas, y presentó CVI significativo (valor 0.88 superior al mínimo requerido), así como puntaje SUS (superior a 70, en este caso 71.5) revelando la aplicabilidad de fanpage a los trabajadores de samu 192 CE. Conclusión: Se espera que esta herramienta pueda ayudar a mejorar la comunicación, promoviendo una mayor integración entre directivos y trabajadores y favorecer la difusión e interiorización de metas y valores, así como de la misión y visión de la institución.

Palabras clave: Comunicación; Fanpage; Publicidad; SAMU.

\section{Introdução}

No final da década de 80 e início da década de 90, começa no Brasil a implantação do modelo norte-americano, adotado principalmente pelo Corpo de Bombeiros Militares (CBM), que trabalha com profissionais não oriundos da área da saúde, porém treinados para atuarem em emergências traumáticas; segundo Martins (2004) veio para suprir uma lacuna do Setor Saúde, inserindo o Setor Segurança Pública como "política compensatória", com escassos investimentos estatais, principalmente com relação aos recursos humanos em detrimento às suas competências constitucionais.

No decorrer do tempo, os socorristas passaram a ser chamados para atender emergências decorrentes de causas naturais, de modo que foi necessário evoluir para o atendimento aos moldes do SAMU francês Martins (2004), visto que os socorristas se tornavam limitados em função de não terem formação na área da saúde.

O modelo francês foi sendo adotado no Brasil, com certas adaptações, com profissionais da área da saúde inseridos na equipe (enfermeiros, técnicos de enfermagem e médicos) (Martins; Prado, 2003; Bau, 2007).

O SAMU no Brasil possui uma Unidade de Suporte Avançado (USA) à vida aos moldes do modelo francês, porém o que o diferencia deste modelo é o fato de possuir uma Unidade de Suporte Básico (USB) à vida, na qual não está presente a figura do médico, e sim um técnico de enfermagem e um motorista socorrista, fato este que diferencia o seu nome, passando de Serviço de Atendimento Médico de Urgência para Serviço de Atendimento Móvel de Urgência.

No SAMU, a equipe de regulação médica tem como competência: julgar e decidir sobre a gravidade de um caso, comunicando via rádio ou telefone, disponibilizando os recursos a serem enviados e orientando o atendimento a ser realizado, além de administrar os meios disponíveis para a prestação do atendimento solicitado, evitando desgaste do sistema pelo envio de recursos insuficientes, ou mesmo, superior à necessidade em questão (Lopes \& Fernandes, 1999).

Em 2002, a Portaria $n^{\circ}$ 2048, que regula as urgências e emergências, veio atualizar as normatizações do APH no Brasil, e é a que está em vigor até o momento. Esta nova portaria estabelece os princípios e diretrizes dos referidos sistemas, tais como critérios de funcionamento, classificação e cadastramento de serviços; Planos Estaduais de Atendimento às Urgências e Emergências, Regulação Médica, APH fixo, APH móvel, atendimento hospitalar, transporte Inter Hospitalar e a criação de Núcleos de Educação em Urgências (Ministério da Saúde, 2002).

Em 2003, a Portaria $n^{\circ} 1864$ institui o componente pré-hospitalar móvel da Política Nacional de Atenção às Urgências, por intermédio da implantação do SAMU 192 em Municípios e Regiões de todo o território brasileiro e a Portaria nº 1863 do mesmo ano, institui a Política Nacional de Atenção às Urgências, a ser implantada em todas as unidades federadas, respeitadas as competências das três esferas de gestão (Ministério da Saúde, 2003)

Quanto ao atendimento pré-hospitalar no Estado do Ceará, conta que a implantação de um serviço móvel de saúde iniciou-se pela capital, Fortaleza em 15 de junho de 1992 mas foi oficializado, com a denominação "SOS Fortaleza", através da publicação da Lei municipal 8.901 de 07 de dezembro de 2004, oportunidade em que foi criado o sistema de transporte para pacientes que necessitavam se submeter a sessões de hemodiálise, quimioterapia e radioterapia (Junqueira, 1997).

A concepção inicial era de transporte de pacientes entre suas residências e a unidade de saúde, não se tratando exatamente de socorro pré-hospitalar especializado de urgência. O "SOS Fortaleza" nasceu inicialmente vinculado à Empresa Municipal de Limpeza e Urbanização (EMLURB) e depois foi vinculado à Secretaria de Transportes do Município, quando os servidores foram lotados na Companhia de Transporte Coletivo (CTC). 
A partir da aprovação das Portarias n 1.864/GM/MS de 2003 e a de nº 2.048 do Ministério da Saúde, que aprovou o Regulamento do Sistema Único de Saúde), implantou-se em todo o país, consequentemente no Ceará, o Serviço de Atendimento Móvel de Urgência, que atende pelo número de telefone 192.

$\mathrm{Na}$ capital cearense, o suporte às urgências é de responsabilidade da própria Secretaria de Saúde Municipal de Fortaleza, enquanto nas demais localidades do Estado fica sob o encargo do governo estadual, que no intuito de aumentar a eficácia do serviço, dividiu-o em bases. Existe uma Central de Regulação como cérebro do serviço de atendimento.

Partem de lá as decisões operacionais, de transporte e remoção, ou seja, é essa central que decide que tipo de viatura será encaminhada ao local da ocorrência, sendo esse o primeiro contato do usuário com o serviço, sendo este por via telefone, e é a partir dos relatos deste contato que serão verificados o tipo de ocorrência (trauma ou clínica) e consequentemente o tipo de intervenção será necessária, de acordo com os critérios anteriormente citados.

Há uma equipe de regulação médica que constitui a Central de Regulação (CR) e se conecta com as equipes móveis: trata-se de um grupo definido como de ação e que tem como objetivo específico decidir o tipo de viatura a ser deslocada até o local da ocorrência, o modo como será o atendimento e o destino da vítima, que receberá os cuidados hospitalares.

A coleta da CR pode ser considerada como sendo o primeiro grande desafio da CR, de forma que a equipe deve, por telefone, verificar informações importantes a partir do relato de um leigo, muitas vezes em estado alterado de humor e sem qualquer tipo de conhecimento técnico. Além disso, os TARMs devem estar tecnicamente treinados para reconhecer falhas e desvios de relato que possam sinalizar situações de trote, casos estes considerados e tratados como crime pela instituição e pela lei civil.

As equipes iniciam o tratamento e estabilização das vítimas e durante todo o atendimento permanecem em contato com a central, de forma a repassar os achados, sinais vitais, sinais e sintomas e as intervenções aplicadas. Essa comunicação auxilia o processo de decisão por parte da CR quanto ao transporte dessa vítima. É atribuição da CR decidir para onde a vítima deverá ser transportada.

O interesse por se melhorar as ferramentas de comunicação dentro do órgão surgiu quando se percebeu a necessidade advinda da gestão do SAMU CE na vivência diária com as bases, ou seja, falhas de transmissão da informação entre trabalhadores e gestão, tal problema interferia diretamente na velocidade, na efetividade e na segurança da comunicação.

A comunicação de eventos importantes era feita através de Comunicação Interna - CI, enviadas por e-mail, impressas e afixadas em mural em cada base pelos coordenadores ou outro responsável. Dessa forma, a comunicação imediata ficava restrita aos plantonistas que estava na base naquele dia, ou seja, os que podiam visualizar o documento, por vezes os trabalhadores não tinham interesse em repassar a informação aos demais, que só iriam ter conhecimento ao chegar para o plantão. Os plantonistas que estavam afastados por férias ou outros motivos, por vezes, simplesmente não tinham acesso a essas informações.

Em contrapartida as informações corriam rapidamente nas bases não oficiais, como as redes sociais, nos perfis pessoais dos trabalhadores, havia uma mudança natural do modo de se compartilhar as informações, trocar vivências/rotinas bem como receber feedback. Respostas tais como confirmações de presença, críticas e sugestões aos eventos ocorridos que nunca chegaram às coordenações por vias oficiais. A partir das falhas encontradas, e da mudança natural vivencias inicia-se o processo de pesquisa sobre a comunicação em rede social e sobre as ferramentas que poderiam ser utilizadas para este fim.

A fanpage foi disponibilizada pela equipe do Facebook® justamente com essa finalidade e percebeu-se que a ferramenta se encaixaria necessidade atual de comunicação, de forma a torná-la mais rápida, acessível, eficiente, eficaz e oficial.

Diante dos expostos o objetivo deste estudo define-se em desenvolver uma fanpage como ferramenta de gestão para comunicação interna verificando a validação de conteúdo e usabilidade. 


\section{Metodologia}

O estudo faz parte da pesquisa de mestrado intitulada: "Construção e validação de uma fan page para o SAMU-CE: uma ferramenta de comunicação institucional", de abordagem metodológica com utilização de dados quantitativos e complementação de abordagem qualitativa no momento da validação.

Diante do Contexto, definiu-se que a pesquisa tivesse um recorte de cenário a sede central do SAMU $192 \mathrm{CE}$, no município do Eusébio, localizado na rua da paz, nº 29. Eusébio é um município brasileiro do estado do Ceará, Região Nordeste do país. Localizado na Região Metropolitana de Fortaleza, a 24 quilômetros da capital, possui $79 \mathrm{~km}^{2}$ de área territorial. Sua população: estimada em 52,667 habitantes. IBGE/2017.

Participaram da pesquisa os trabalhadores do SAMU 192 CE. Conforme o quadro 01. No SAMU 192 CE, tem-se um número total de 1.134 trabalhadores $(\mathrm{N}=1.134)$ dos que circulam na ambulância e também os que atuam na Central de Regulação Médica de Urgências. Sendo composta por profissionais ( $n=117)$ das cinco categorias, médicos ( $n=15)$, enfermeiros $(\mathrm{n}=25)$, técnicos de enfermagem $(\mathrm{n}=37)$, condutores $(\mathrm{n}=28)$ e os Técnicos Auxiliares de Regulação Médica da Central de Regulação Médica de Urgência ( $\mathrm{n}=12)$.

Este instrumento foi elaborado pelo próprio pesquisador e buscou dados de identificação com as variáveis: Profissão, Tempo de Experiência na função, Maior Titulação, Sexo e Idade. No questionário constava também uma pergunta de múltipla escolha e uma pergunta aberta.

Com a aceitação, eles um questionário semiestruturado e o TCLE que estava em duas vias, uma via deveria ficar com o participante, a outra deveria ser assinada e entregue ao pesquisador.

O processo de Aplicação do Questionário se deu por conveniência e não probabilística, todos os profissionais que estavam presentes nos dias da aplicação dos questionários foram convidados e alguns aceitaram participar da pesquisa. Os questionários foram aplicados pelo próprio pesquisador.

Os critérios de inclusão e exclusão foram constituídos de profissionais concursados e contratados através da Cooperativa que atuam no SAMU 192 CE, nos municípios do Eusébio, Maracanaú e Caucaia. Os que aceitaram participar da pesquisa assinando o Termo de Consentimento Livre Esclarecido (TCLE), modelo anexado.

Os dados do questionário foram submetidos a análise estatística com frequência e percentual, utilizando-se o Excel Versão 2016. A apresentação foi em forma de quadro e discutida descritivamente e interpretada à luz da literatura pertinente.

A análise da Validação de conteúdo foi realizada levando em Consideração ao IVC (Fering, 1994) e a Análise dos resultados da Validação da Usabilidade (Chuva de ideias) foi através da descrição.

\section{Resultados}

A busca pelos dados se deu a partir do uso de um questionário, com o seguinte perfil: Dos profissionais que responderam ao questionário, $35 \%$ do quantitativo é composto por profissionais tidos como novatos, ou seja, com menos de 1 ano de serviço, enquanto $21 \%$ tem mais de 6 anos de serviço. A maior parte dos profissionais que responderam estão entre essa faixa de mais de 1 ano e menos de 5 anos, esses constituem constituindo $44 \%$ do total.

Constatou-se que dos respondentes, 74 eram do sexo feminino e 43 do sexo masculino, constituindo $63 \%$ e $37 \%$ do total, respectivamente. Quanto às titulações, a maioria, seguindo o padrão das categorias, foi de Ensino Médio, sendo 77 participantes com essa titulação. Seguem 40 participantes com apenas a Graduação e 37 sendo especialistas. 17 participantes fizeram residência e 4 são mestres. Em significativo menor número, são 3 com doutorado e 2 com pós-doutorado.

Foram listadas também as categorias profissionais e as titulações dos respondentes e constatou-se que a maior parte eram profissionais Técnicos de Enfermagem, que foram caracterizados como profissionais de Ensino Médio. Somaram 37 
respondentes, o equivalente a $32 \%$ do total. Enquanto enfermeiros e condutores somaram $21 \%$ e $25 \%$ do total respectivamente. Já os médicos e Técnicos Auxiliar de Regulação Médica, em menor número, somaram, 13\% e 10\% respectivamente.

Tratando-se da faixa etária, constatou-se que a maioria dos profissionais que responderam ao questionário tem idade entre 30 e 40 anos, o que corresponde a 70\% do total. Apenas 7\% estão na faixa entre 20 e 30 anos, enquanto os demais têm entre 40 e 50 anos, representando $23 \%$ do total.

Quanto ao questionário, $40 \%$ dos respondentes disseram receber informações via Comunicação Interna - CI e por telefonemas, enquanto $24 \%$ disseram receber informações diretamente do website da Secretaria Estadual de Saúde - SESA. Do total, $36 \%$ responderam receber informações por outros meios.

Sobre a qualidade da informação recebida, apenas $26 \%$ dos profissionais que responderam ao questionário afirmaram que as informações recebidas são claras e objetivas. Os demais, $74 \%$ dos respondentes são contrários a esta afirmação, ou seja, responderam que as informações não são claras e objetivas.

Ao serem questionados sobre o tipo de informação que gostaria de receber, a pesquisadora obteve as seguintes respostas: Chama a atenção 6 respostas, $2 \%$ que foram dadas exatamente da mesma forma, agenda da Educação Permanente, Vídeos Institucionais, Informativos, Vídeos Educativos, Calendário de Reuniões e Planejamento Estratégico do SAMU.

\section{Construção da fanpage}

A pesquisa avaliou criticamente os critérios e métodos empregados no desenvolvimento dos vários estudos selecionados para determinar se são válidos metodologicamente, e se são pertinentes a realização do objeto de pesquisa.

Para elaborar uma revisão integrativa relevante, é necessário que as etapas a serem seguidas estejam claramente descritas. O processo de elaboração da revisão integrativa encontra-se bem definido na literatura.

\section{Passos de construção da fanpage}

a) Escolha do título

b) Escolha dos administradores

c) Escolha da imagem do perfil e imagem de capa

d) Descrição da página e objetivos

e) Determinação das regras de segurança e privacidade da página

f) Determinar método de divulgação 
Figura 1 - Passos da construção da fanpage.

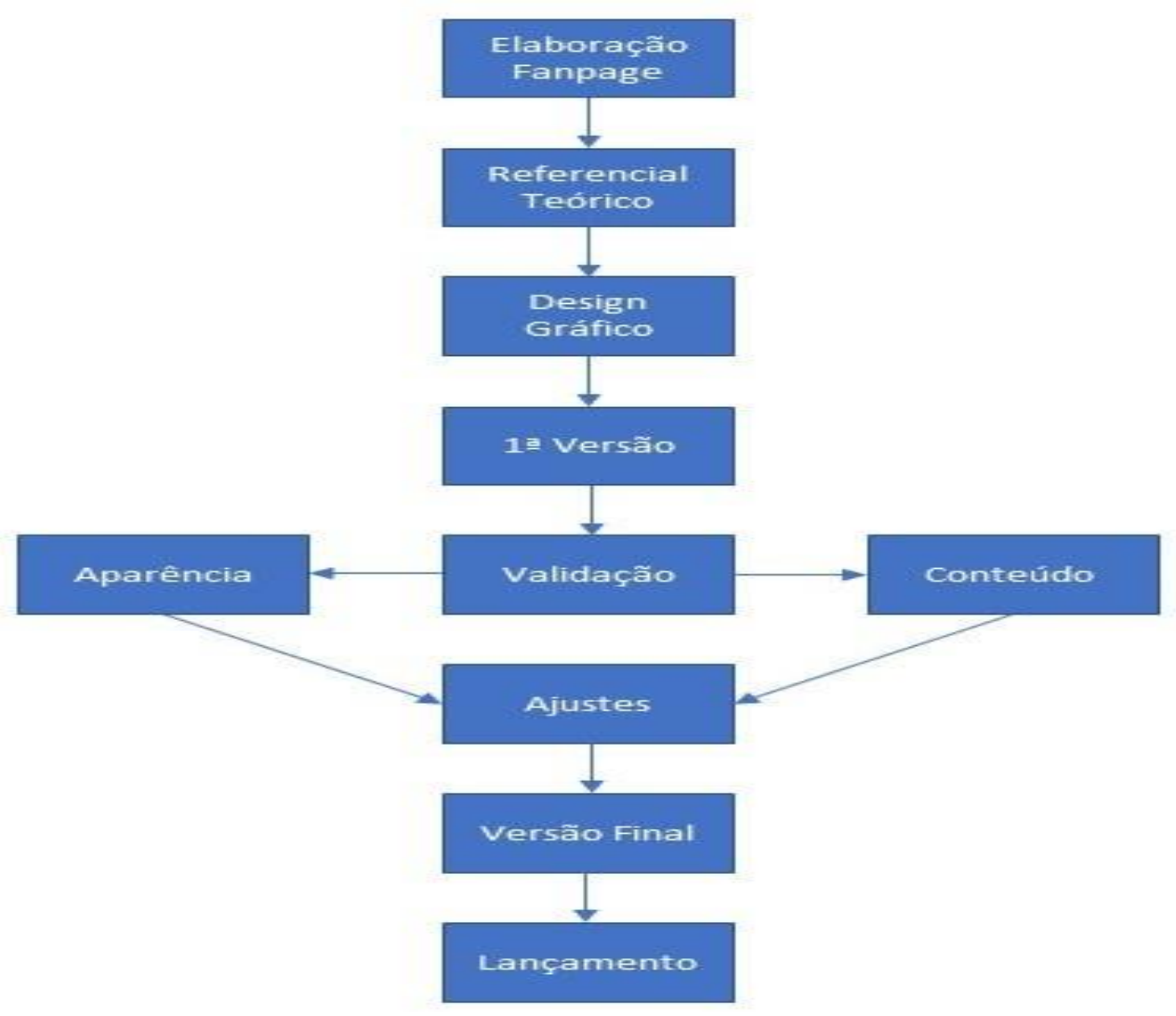

Fonte: Elaborada pelas autoras.

Em primeiro momento, aplicou-se um questionário com perguntas sócias demográficas, incluísse-se as respostas relacionadas: Agenda da Educação Permanente, Aniversariantes do mês; Vídeos institucionais; Informativos; Mapeamento do Serviço de Urgência; Vídeos educativos; Fotos do serviço; Artigos científicos; Calendário de Reuniões. Da revisão complementou-se em relação aos serviços de urgência e Emergência no mundo e no Ceará abordando os assuntos comunicação e Marketing.

\section{Validação da ferramenta fanpage}

O produto foi validado após sua construção e submetido a validação de usabilidade e a validação de Conteúdo com Juízes acadêmicos, publicitários, comunicação e marketing e do SAMU, num total de sete juízes.

A validação da Usabilidade foi realizada com a População do SAMU, após esses momentos foram realizadas adaptações das respostas dos juízes a fanpage, e então, realizou-se o produto.

\section{Validação de usabilidade com os profissionais}

A ferramenta construída trata-se de uma fanpage com a finalidade de facilitar a comunicação interna do SAMU 192 CE. Esse veículo de comunicação foi desenvolvido a partir da realidade encontrada e dos resultados achados através do questionário aplicado. Fazendo-se necessário à sua validação em uma etapa.

Para avaliar a ferramenta criado foi testada sua usabilidade. A avaliação da usabilidade foi mediada por meio do questionário System UsabilityScale (SUS) criado por John Brooke em 1986 e validado no Brasil por Tenório et al. (2010). 
O questionário SUS é usado para avaliar produtos, serviços, hardware, software, websites e aplicações. Ele consiste em dez perguntas e para cada uma delas, o usuário pode responder em uma escala de 1 a 5 , onde 1 significa Discordo Completamente e 5 significa Concordo Completamente. Para calcular a usabilidade, subtrai-se 1 da pontuação para as respostas ímpares e para as respostas pares subtraia a resposta de 5. Para obtenção da média final, multiplica-se o valor encontrado por 2.5. A média do SUS é 68 pontos

Resultados da validação de usabilidade - A validade de usabilidade é definida por Nielsen (2003) quando é um atributo de qualidade que avalia a facilidade de uso de uma interface, sendo definida por cinco componentes: capacidade de aprendizagem (facilidade de utilizar o sistema pela primeira vez); eficiência (agilidade para executar as tarefas); memorização (processo de recordar como utilizar o sistema, após um período sem utilizar); erros (ausência de erros apresentados pelo sistema); satisfação (design com agradabilidade).

Autores como Sordi e Meireles (2010) propõem que o nível de usabilidade de um sistema pode ser alcançado avaliando-se características como a facilidade de aprendizagem da operação e a facilidade e eficiência de uso da interface.

Nesse sentido, foi desenvolvida o questionário SUS (System UsabilityScale) em 1986, por John Brooke, no laboratório da Digital Equipment Corporation, no Reino Unido. É um questionário composto por 10 itens, com 5 opções de respostas (Sauro, 2009). A escala é uma tecnologia independente e já foi testado em hardware, software de consumo, sites, telemóveis, URAs e até as páginas amarelas. Tornou-se um padrão da indústria com referências em mais de 600 publicações (Sauro, 2009).

Figura 2 - Capa da fanpage.

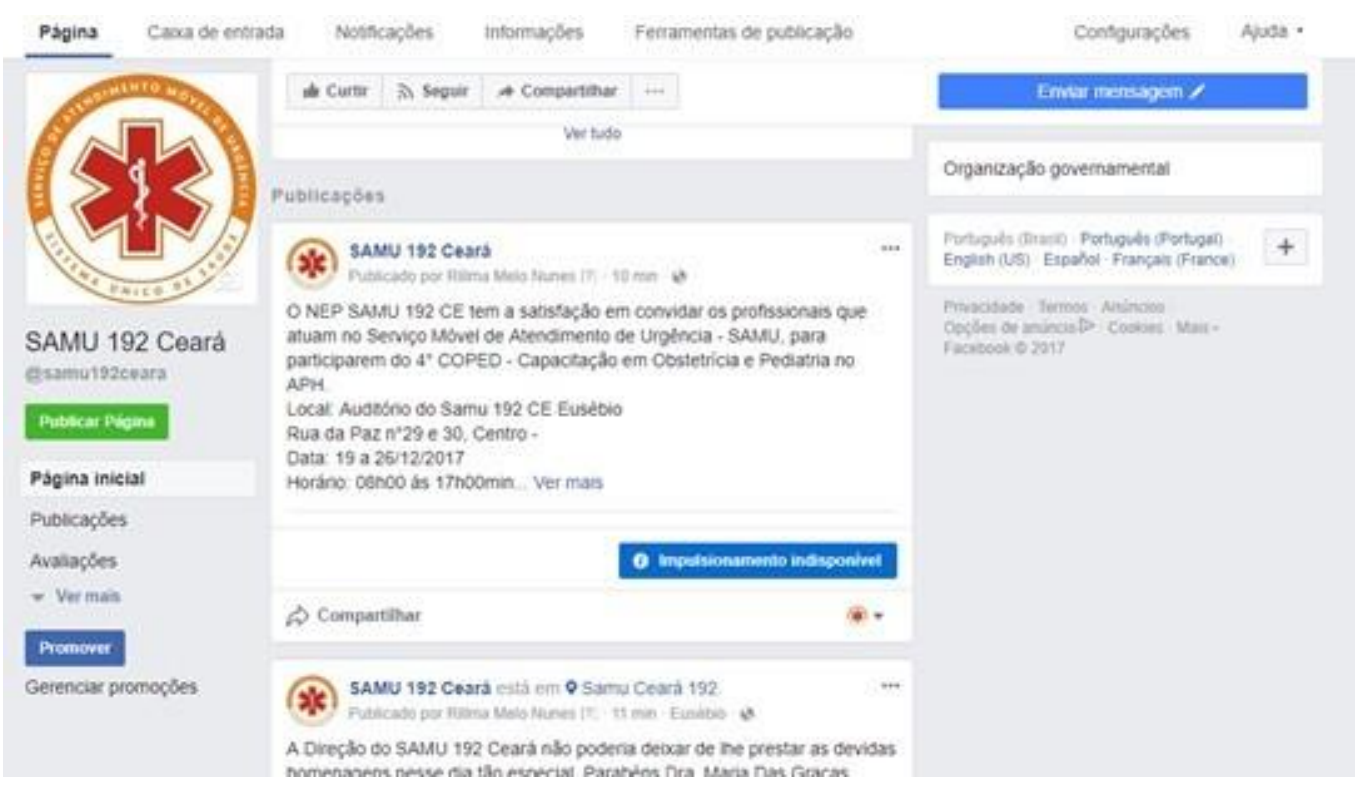

Fonte: Página SAMU 192 Ceará, Facebook, 2017.

A manutenção e alimentação das informações da fanpage é feita pelos próprios gestores, a fim de validar as informações repassadas. 
Figura $3-1^{\text {a }}$ postagem da fanpage.

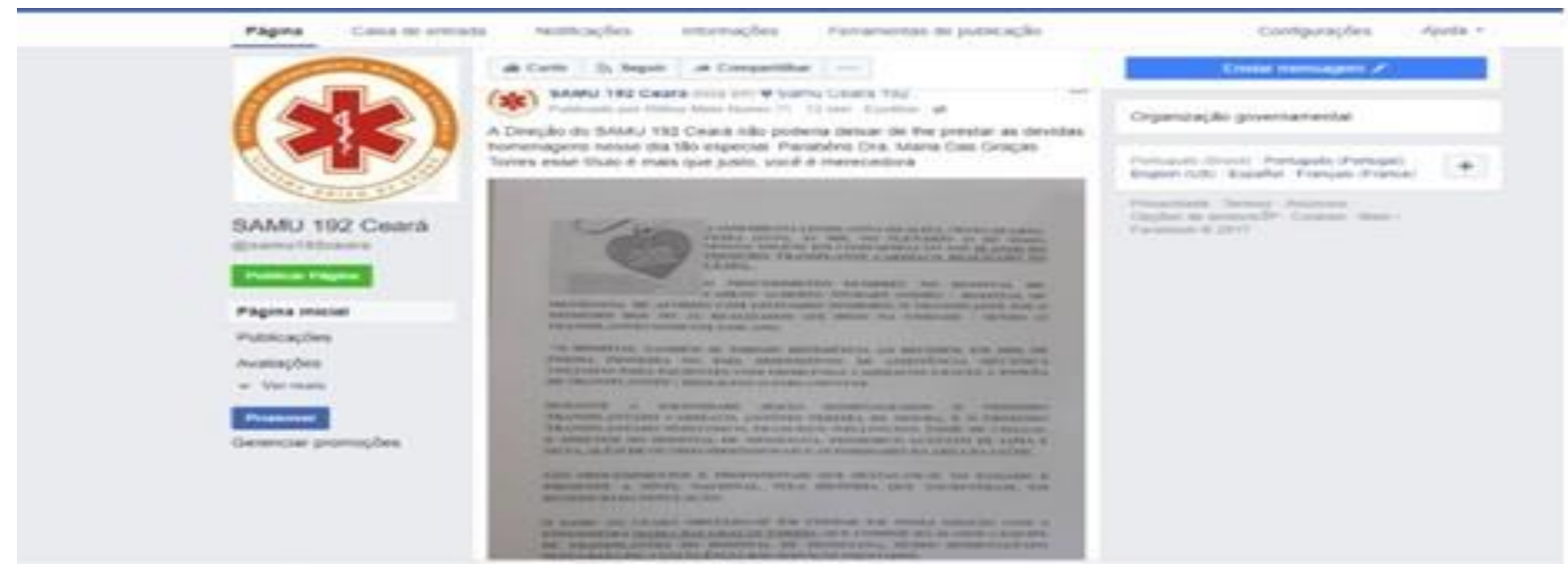

Fonte: Página SAMU 192 Ceará, Facebook, 2017.

Além do conteúdo informativo, a página também promove interação entre os profissionais. Na imagem acima, observa-se a homenagem feita a uma servidora por tempo de serviço.

Figura $4-3^{\text {a }}$ postagem da fanpage.

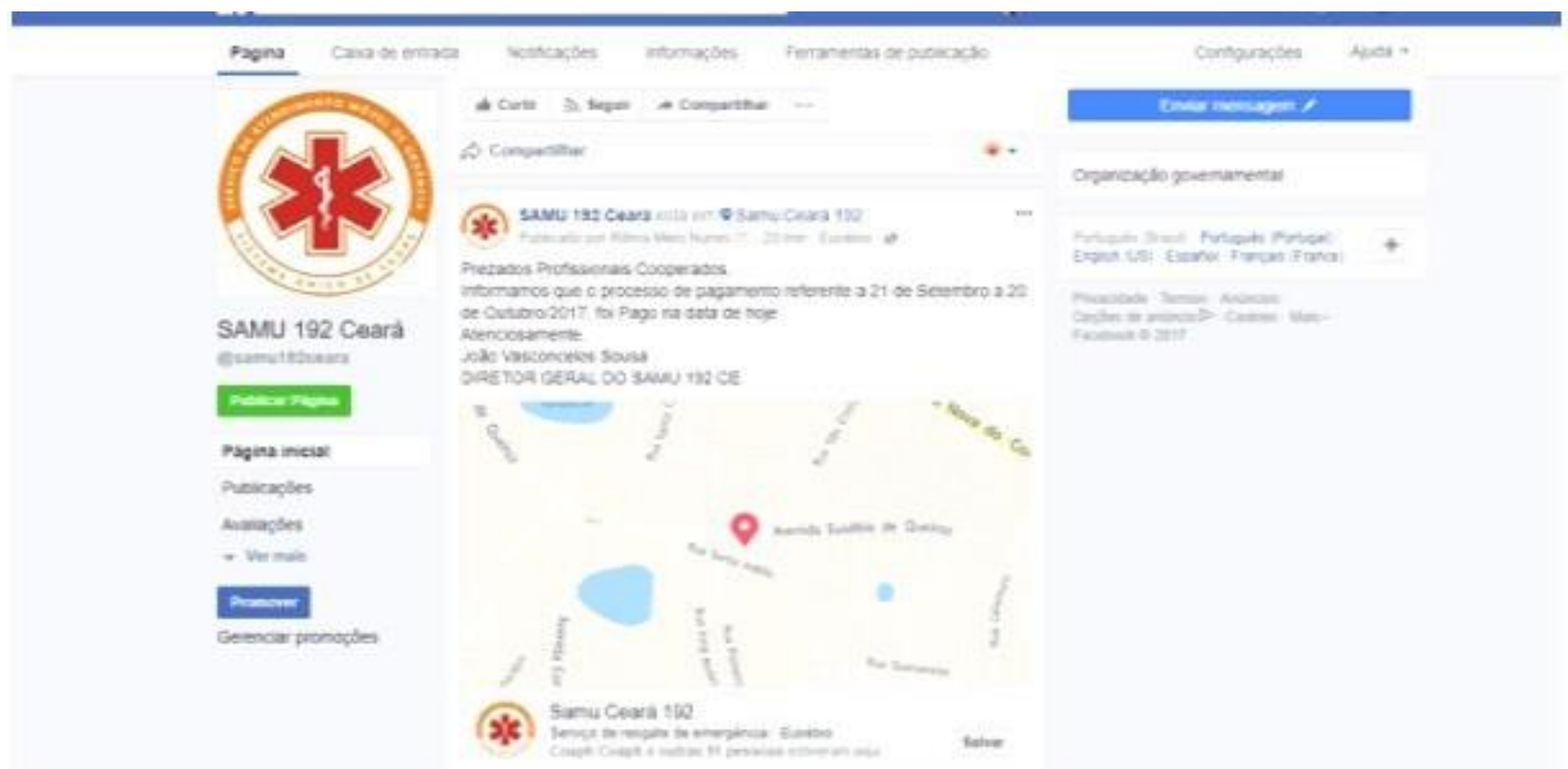

Fonte: Página SAMU 192 Ceará, Facebook, 2017.

Postagens oficiais podem ser acompanhadas por informações complementares como endereço, que podem ser acessadas via GPS, por exemplo, aumentando a interação da página com as tecnologias móveis dos usuários.

\section{Discussão}

A Internet é um ecossistema digital caracterizado por arquitetura descentralizada, multiplicação de fontes de emissão, disponibilização ininterrupta de dados, sons e imagens, utilização simultânea e interações singulares.

A utilização da internet para fins de comunicação interna é totalmente viável contanto que se tenha o cuidado com a formalização e oficialização do conteúdo, caso contrário, ficará comprometida sua credibilidade. 
A internet, em conjunto com as tecnologias relacionadas, tais quais os aplicativos de conversação e as redes sociais reestruturaram a comunicação como a conhecemos, tornando-a imensuravelmente mais rápida e acessível. Isso mudou as relações sociais e profissionais no mundo todo. $\mathrm{O}$ fácil compartilhamento, o acesso livre e irrestrito e a velocidade com que as informações são manipuladas na rede mundial de internet mudou a forma com que as informações são trabalhadas. A utilização da internet como meio de comunicação interna pelas instituições tornou-se imprescindível para o melhor funcionamento dos serviços. Nesse contexto, torna-se fundamental que sejam tomadas medidas que garantam a qualidade, a preservação e a disseminação correta das informações institucionais, principalmente quando trata-se de órgão público.

Atualmente, a TI como suporte ao sistema de informação, no SAMU 192 CE denomina-se NUINF- Núcleo de Informática, subordinado a SESA - Secretaria de saúde do estado do Ceará. Onde a troca de informações e acessibilidades são trabalhadas apresentando o mínimo de falhas possíveis, sob pena de gerar defasagem na compilação de dados caso haja falta de integração intersetorial. A adoção de tecnologias de suporte a gestão, proporcionam a análise de atividades relacionadas a equipe de colaboradores que compõem o quadro funcional do SAMU 192 Ceará, utilizando-se de informações internas e operacionais construindo cenário completo de informações e indicadores, que garantem abordagem adequada da atividade "linha de frente" alinhada diretamente a equipe de gestores.

Sabe-se que a comunicação interna integra, motiva o colaborador e auxilia a empresa a atingir as suas metas, priorizando os esforços e ajudando a tomar as decisões de forma eficiente (Torquato, 2002).

Contudo, a aceleração tecnológica torna a comunicação interna cada vez mais complexa e exige uma postura flexível, pois precisa desenvolver um sentimento de participação em todos que integram a empresa, e para que isso ocorra é necessária a escolha do canal adequado para disseminar a informação, para que não ocorram distorções durante o processo ocasionando problemas, com base nos fatores explanados entendemos que interface da fanpage unifica os sistemas e viabiliza a simulação e otimização das atividades facilitando a gestão controle de procedimentos operacionais, registros e especificações garantindo a segurança das informações, gerando indicadores fidedignos de resultados, reduzindo o desperdício de tempo, viabilizando a simulação e otimização por meio de uma interface simples e confiável. Portanto, aliar ferramenta tecnológica as necessidades do serviço baseada em evidências, permite a execução de projetos multiplantas.

A base Regional do SAMU 192 CEARÁ, localizada no município do Eusébio, abriga os setores administrativos e operacionais da instituição: Direção Geral, administrativa e financeira, Central de Regulação, Recursos Humanos, Núcleo de Educação Permanente - NEP, Núcleo de Informática - NUINF, Logística, CME e Distribuição, Almoxarifado, Arquivo e as coordenações médica, de enfermagem e de transporte.

O SAMU 192 CEARÁ está instalado em 62 municípios. Nas bases Regionais e descentralizadas, atendendo 126 cidades, de Norte a Sul no estado do Ceará e conta com quadro de 1.414 trabalhadores, entre médicos, enfermeiros, técnicos de enfermagem. 
Figura 5 - Bases regionais e descentralizadas do SAMU 192 -CE.

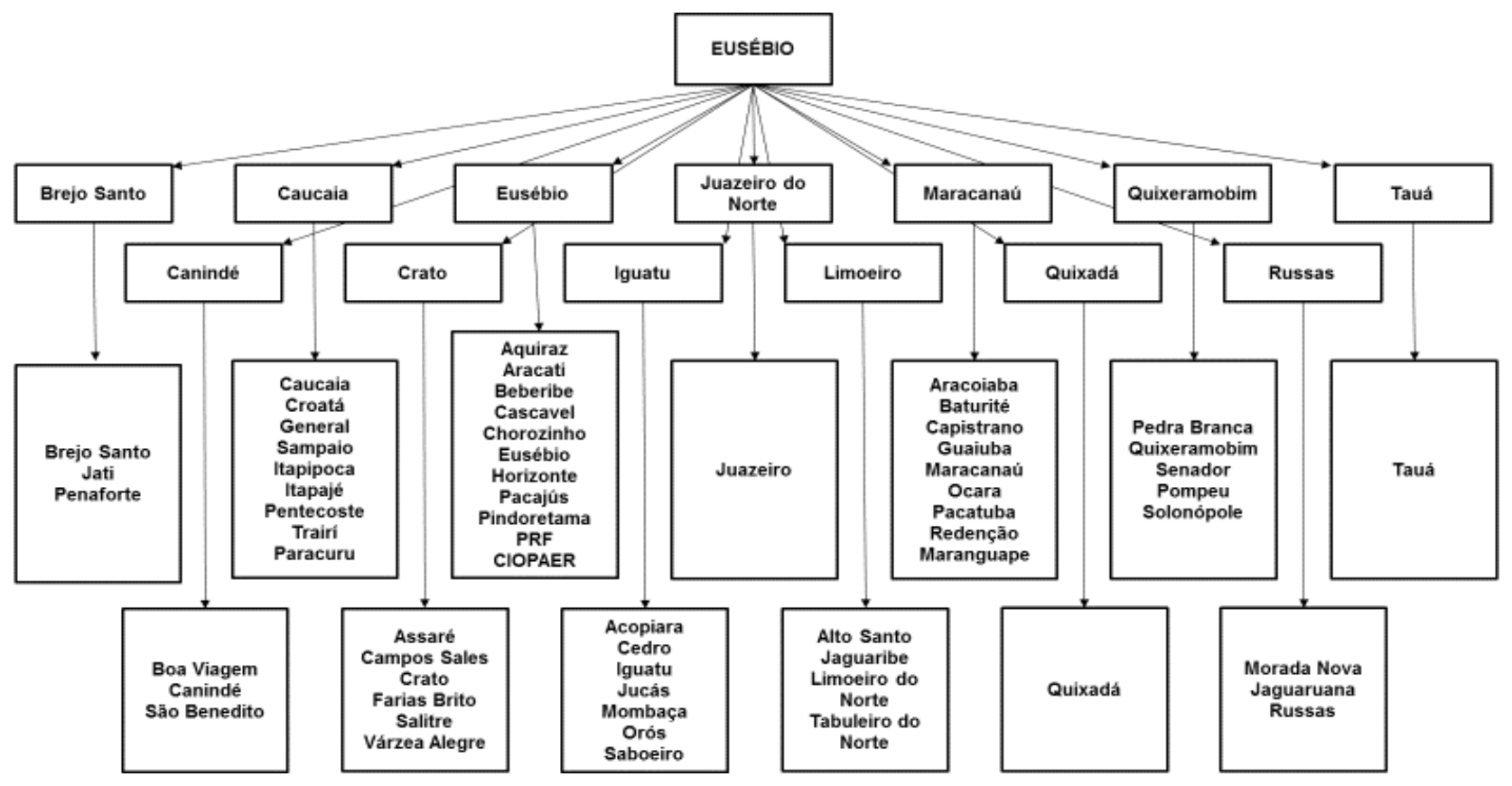

Fonte: Elaborada pelas autoras.

O SAMU $192 \mathrm{CE}$, possui duas unidades de atendimento aeromédico, já que em algumas situações exigem uma intervenção mais rápida, há o apoio do helicóptero da Secretaria de Segurança Pública e Defesa Social do Estado (SSPDS) / Coordenadoria Integrada de Operações Aéreas (CIOPAER).

Figura 6- Composição operacional do SAMU 192-CE.

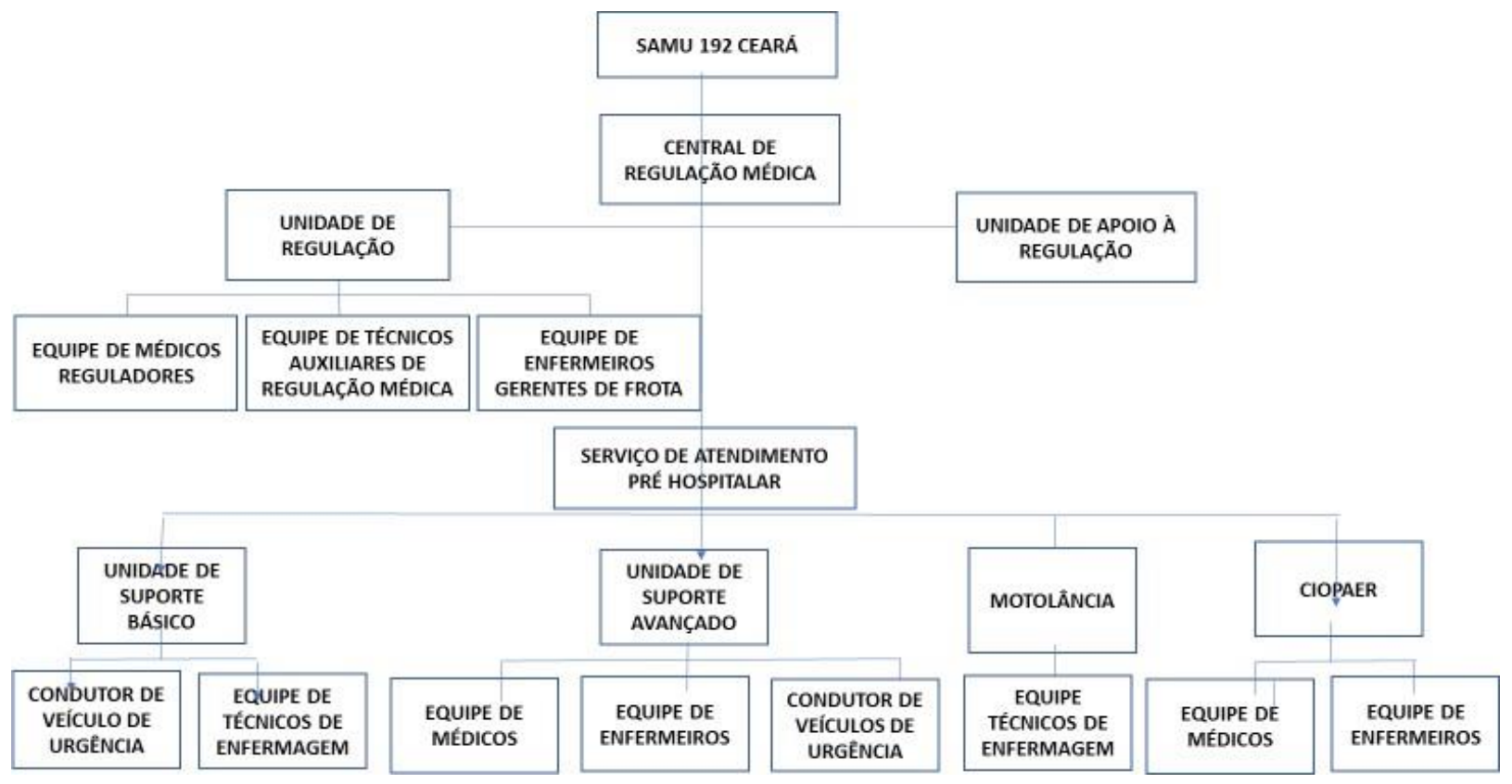

Fonte: Elaborada pelas autoras.

Além disso, o SAMU 192 Ceará tem um convênio com a Polícia Rodoviária Federal (PRF) no Estado que conta com mais uma unidade (unidade de saude básica) USA, priorizando o atendimento das ocorrências nas estradas vicinais que cortam todo o interior. 
Figura 7 - Operacional da central de regulação médica do SAMU 192- C.

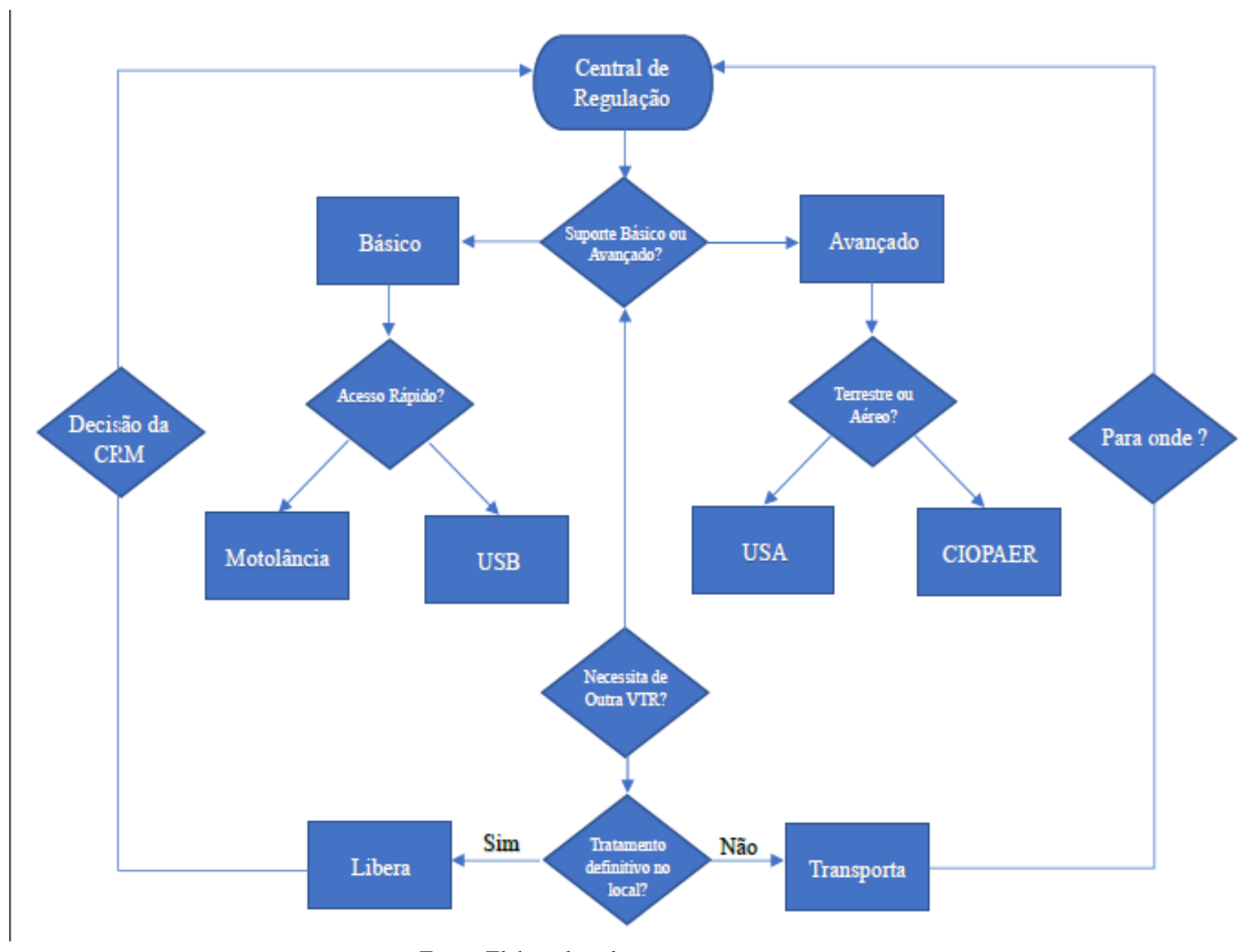

Fonte: Elaborada pelas autoras.

Outrossim, a comunicação Interna se refere às interações, os processos de trocas, os relacionamentos dentro de uma empresa ou instituição. Também chamada de Endocomunicação, a Comunicação Interna é responsável por fazer circular as informações e o conhecimento de forma verticalmente, ou seja, da direção para os níveis subordinados; e horizontalmente, entre os empregados de mesmo nível de subordinação.

Porém, adotando-se um olhar estratégico, a comunicação não é apenas uma forma de repassar informações, mas uma importante ferramenta de interiorização dos valores, da cultura e do comportamento padrão dos trabalhadores da instituição, ou seja, é um canal do qual os gestores podem utilizar para modelar os trabalhadores nos moldes de seu local de trabalho.

Observando-se o cenário de fluxos de comunicação interna em unidades de saúde na perspectiva de organismos críticos e reivindicantes da sociedade civil, é possível perceber que ambientes compartilhados favorecem a tomada de decisão, os convívios participativos e reciprocidades.

Para que isto ocorra, a comunicação entre a gestão e os trabalhadores deve ser direta, clara, objetiva e de duas vias, ou seja, em forma de diálogo contínuo e participativo, de maneira que seja possível disseminar as metas, a missão, a visão e os valores da instituição sem interferências e/ou distorções. 
Tabela 1 - Distribuição do grupo de especialistas segundo o sexo, faixa etária, profissão, qualificação profissional e tempo de experiência, publicação em periódico e participação em grupo de pesquisa. Eusébio, Ceará. 2017.

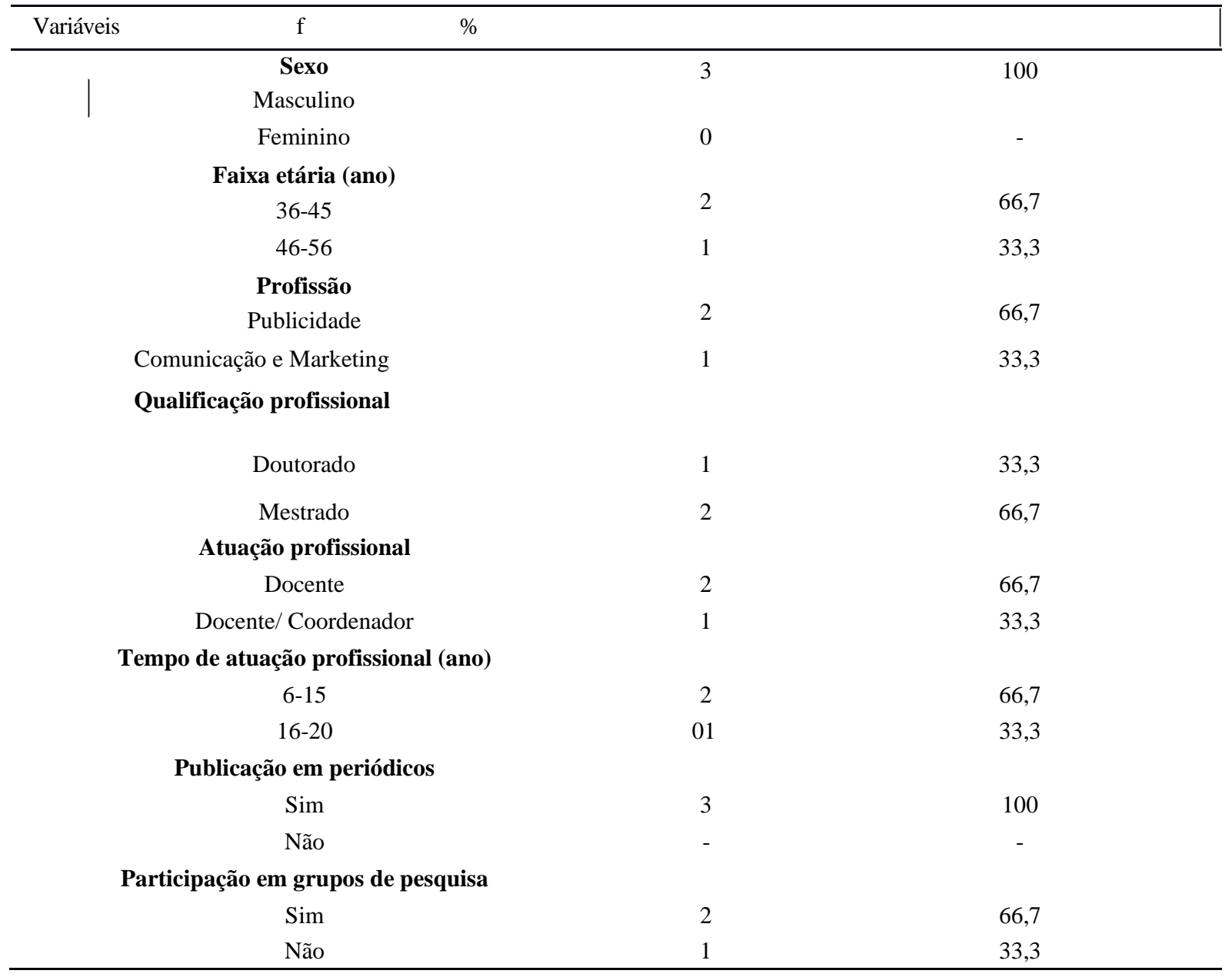

Fonte: Elaborada pelos autores.

De acordo com a tabela 1, percebe-se que todos os especialistas eram do sexo masculino (100\%). Em relação a Profissão 02 especialistas eram publicitários $(66,7 \%)$, com idade de 36 a 45 anos $(66,7 \%)$. No que concerne à qualificação profissional, 01 possuía doutorado em Mídias e Gestão da Comunicação e 02 com mestrado, em Marketing Digital e Programa de Comunicação.

Observa-se a preocupação dos profissionais com a aquisição de conhecimentos, onde a constante atualização profissional reflete na melhoria dos serviços prestado, permitindo organizar e realizar práticas respaldadas na pesquisa.

Quanto à atuação profissional, dois especialistas eram exclusivamente, docente, outro atuava na docente/coordenador, todos com artigos publicados e dois participavam de grupos e pesquisa. Em relação ao tempo de atuação 02 profissionais especialista com 6 a 15 anos de atuação.

Após a análise dos questionários de avaliação referentes à caracterização dos especialistas, constatou-se que um atingiu 9 pontos, dois alcançaram e dois a 8 pontos.

Sabe-se da dificuldade em se definir especialistas para estudos de validação, pois, além de não haver um consenso na literatura, também existe a barreira referente à formação e ao aprimoramento do profissional. Entretanto a amostra se mostrou qualificada, aliando, além da experiência profissional, o comprometimento com as atividades académicas e de pesquisa.

Em relação à validade do veículo de comunicação construído, foi solicitado aos especialistas para avaliarem no tocante à clareza, aplicabilidade, concisão, imagem, linguagem compreensível. Desse modo, foi realizada a validade de 
conteúdo da ferramenta. Para isso, foi foram convidados inicialmente 07 pessoas para atuarem como juízes neste estudo, contudo apenas 03 encaminharam o material de forma devolutiva.

O material para avaliação dos juízes foi construído com base nos itens que compõem o protocolo de acordo com os pressupostos de Stetler (1998): clareza, concisão, sequencialidade, universalidade, aplicabilidade na prática, linguagem compreensível, condutas estabelecidas quanto às ações e os executores (baseadas nos melhores níveis de evidência científica).

A resposta do instrumento para avaliação da ferramenta foi disposta numa escala tipo Likert, com cinco níveis de suporte, sendo esses: 1. Inadequado; 2. Parcialmente inadequado; 3. De algum modo inadequado; 4. Adequado; 5. Totalmente adequado.

As respostas dos juízes foram agrupadas e em seguida calculado o IVC de acordo com cada atribuição.

Quadro 1 - Distribuição das respostas dos juízes na validação de conteúdo instrumento para cada uma das questões apresentadas. Eusébio, 2017.

\begin{tabular}{|l|l|c|}
\hline & \multicolumn{1}{|c|}{ ITENS } & IVC \\
\hline 01 & A ferramenta está clara e concisa. & 0,66 \\
\hline 02 & $\begin{array}{l}\text { A fanpage pode ser utilizado pelos gestores e trabalhadores do } \\
\text { SAMU 192 CE como veículo de comunicação. }\end{array}$ & 1,00 \\
\hline 03 & Gera conteúdo de qualidade e relevância para o seu público. & 0,66 \\
\hline 04 & $\begin{array}{l}\text { A linguagem utilizada é compreensível para os usuários que iram } \\
\text { acessá-las. }\end{array}$ & 1,00 \\
\hline 05 & Oferece mídia audiovisual atrativa. & 1,00 \\
\hline 06 & As imagens oferecem qualidade e fidelidade. & 1,00 \\
\hline 07 & As postagens na fanpage comtemplam a ética e as boas práticas de & 1,00 \\
\hline 08 & Oferece conteúdo que motiva, educa e prenda a atenção dos usuários. & 0,66 \\
\hline 09 & Existe uma frequência constante na produção de conteúdo & 0,66 \\
\hline
\end{tabular}

Fonte: Elaboração própria adaptado Stetler (1998).

Ao final realizou-se a validação de conteúdo que recebeu pontuação global de 0,85 e a maior parte dos itens (5 itens) apresentou percentual de $100 \%$. Os itens que receberam menor pontuação foram os itens $1,3,8$ e 9 , portanto foram descartados.

Em um estudo realizado por Souza (2015) os itens da validação de conteúdo que estavam distribuídos em cinco categorias que avaliação um álbum seriado recebeu pontuação global de 0,88 pelos especialistas e apresentou apenas três itens com validação de conteúdo abaixo do que preconiza a literatura, ou seja, abaixo de 0,78\% (Polit; Beck, 2011). Dessa forma, acredita-se que o veículo de comunicação proposto está em conformidade com os parâmetros estabelecidos na literatura.

Assim, diante das respostas dos juízes e dos valores globais atribuídos a fanpage, percebe-se que eles consideraram o instrumento bem estruturado. Foram dadas recomendações e sugestões no sentido de aperfeiçoar o instrumento. Cada observação realizada pelos especialistas foi analisada criteriosamente pela pesquisadora e pela orientadora, e aceita quando aconteceu a concordância entre ambas, de posse de tais sugestões as mesmas adequadas ao veículo de comunicação. 
Figura 8 - Síntese dos valores corrigidos por item para cada participante. esses valores da escala são de 1-20.

\begin{tabular}{|c|c|c|c|c|c|c|c|c|c|c|c|c|c|c|c|c|c|c|c|c|}
\hline \multirow[t]{2}{*}{ Afirmações } & \multicolumn{20}{|c|}{ Participantes } \\
\hline & 1 & 2 & 3 & 4 & 5 & 6 & 7 & 8 & 9 & 10 & 11 & 12 & 13 & 14 & 15 & 16 & 17 & 18 & 19 & 20 \\
\hline $1 \mathrm{AF}$ & 4 & 4 & 4 & 4 & 4 & 4 & 4 & 3 & 3 & 4 & 3 & 3 & 4 & 3 & 3 & 4 & 4 & 4 & 4 & 3 \\
\hline $2 \mathrm{AF}$ & 3 & 3 & 3 & 3 & 3 & 3 & 3 & 3 & 3 & 4 & 3 & 3 & 3 & 3 & 3 & 4 & 4 & 3 & 4 & 4 \\
\hline $3 \mathrm{AF}$ & 2 & 3 & 2 & 3 & 3 & 3 & 3 & 3 & 2 & 3 & 3 & 3 & 2 & 3 & 3 & 3 & 3 & 4 & 4 & 4 \\
\hline $4 \mathrm{AF}$ & 1 & 2 & 1 & 1 & 1 & 1 & 1 & 1 & 1 & 1 & 2 & 1 & 1 & 1 & 1 & 0 & 1 & 3 & 1 & 3 \\
\hline $5 \mathrm{AF}$ & 3 & 3 & 3 & 3 & 3 & 3 & 3 & 4 & 2 & 3 & 3 & 3 & 3 & 4 & 3 & 3 & 3 & 3 & 3 & 3 \\
\hline $6 \mathrm{AF}$ & 3 & 4 & 4 & 4 & 4 & 3 & 4 & 4 & 3 & 3 & 3 & 3 & 3 & 4 & 4 & 4 & 3 & 4 & 4 & 4 \\
\hline $7 \mathrm{AF}$ & 3 & 3 & 3 & 3 & 3 & 3 & 3 & 4 & 3 & 3 & 3 & 2 & 3 & 3 & 3 & 3 & 3 & 3 & 3 & 4 \\
\hline $8 \mathrm{AF}$ & 3 & 3 & 3 & 3 & 3 & 3 & 3 & 3 & 4 & 3 & 3 & 2 & 3 & 3 & 3 & 3 & 3 & 3 & 4 & 4 \\
\hline $9 \mathrm{AF}$ & 3 & 3 & 4 & 4 & 4 & 3 & 4 & 4 & 3 & 3 & 3 & 3 & 3 & 3 & 3 & 4 & 4 & 4 & 4 & 4 \\
\hline $10 \mathrm{~F}$ & 1 & 2 & 1 & 1 & 2 & 1 & 1 & 1 & 2 & 2 & 1 & 1 & 1 & 1 & 1 & 1 & 1 & 1 & 1 & 1 \\
\hline Totalização & 26 & 30 & 28 & 29 & 30 & 27 & 29 & 30 & 26 & 29 & 27 & 24 & 26 & 28 & 27 & 29 & 29 & 32 & 32 & 34 \\
\hline Pontuação SUS & 65 & 75 & 70 & 72,5 & 75 & 67,5 & 72,5 & 75 & 65 & 72,5 & 67,5 & 60 & 65 & 70 & 77,5 & 72,5 & 72,5 & 80 & 80 & 85 \\
\hline
\end{tabular}

Fonte: Elaborada pelos autores.

Assim, considerando a média global obtida do instrumento, encontrou-se o valor médio de 71,5 para a validação de conteúdo da ferramenta realizada com os usuários do SAMU 192 CE, nas bases regionais (Eusébio/ Maracanaú e Caucaia).

As pontuações do SUS têm um aporte de 0 a 100, em que menor que 51 é considerado ruim, maior que 71 é bom, maior que 86 é excelente e maior que 91 é o melhor alcançável (Grossi; Pisa; Marin, 2014).

Dessa forma, diante dos valores obtidos acredita-se que a utilização da fanpage proposta, possa vir a ser uma ferramenta produtora de informações, comunicação e conhecimento.

\section{Considerações Finais}

Ao término deste estudo, que versou a respeito da construção e validação de uma ferramenta de comunicação para o SAMU 192 CE, apresentam-se a seguir algumas conclusões: a revisão integrativa realizada foi fundamental para encontrar dados e informações relevantes referentes ao constructo em estudo bem como subsidiar a construção e validação de uma ferramenta de comunicação, foi fundamental para direcionar sua estruturação. Quanto as validações, primeiramente a de Conteúdo recebeu pontuação global de 0,85 e a maior parte dos itens (5 itens) apresentou percentual de 100\%. Os itens que receberam menor pontuação foram os itens 1,3, 8 e 9, e foram descartados.

No que diz respeito a validação, acredita-se que o veículo de comunicação proposto está em conformidade com os parâmetros estabelecidos na literatura.

Em relação a Fanpage os juízes especialistas em suas respostas e os valores globais atribuídos a fanpage, consideraram o instrumento bem estruturado. Cada observação realizada pelos especialistas foi analisada criteriosamente, e aceita quando aconteceu a concordância entre ambas, de posse de tais sugestões as mesmas adequadas ao veículo de comunicação.

Os profissionais do SAMU que responderam aos instrumentos da usabilidade com a chuva de ideias, definiram a relevância da aplicabilidade da Fanpage para melhoria da Qualidade da atenção do SAMU. Considerando a média global obtida do instrumento, encontrou-se o valor médio de 71,5 para a validação de usabilidade do instrumento realizada com os trabalhadores do SAMU $192 \mathrm{CE}$.

As pontuações do SUS têm um aporte de 0 a 100, em que menor que 51 é considerado ruim, maior que 71 é bom, maior que 86 é excelente e maior que 91 é o melhor alcançável). Diante dos valores obtidos acredita-se que a utilização da 
fanpage proposta, possa vir a ser uma ferramenta produtora de informações, comunicação e conhecimento, sua aplicabilidade será realizada com a permissão da direção do SAMU 192 CE e registrada na Universidade Estadual do Ceará.

\section{Referências}

Albino, R. M. \& Riggenbach, V. (2004). Medicina de Urgência - passado, presente, futuro. Arquivos Catarinenses de Medicina, Santa Catarina. 33 (3), 15 -7.

Bau, L. M. (2007). Todo cuidado é pouco. Revista Emergência. São Paulo, n3, p. 56-61.

Ministério da Saúde. (2003). Portaria MS 1863/03, de 29 de setembro de 2003. Institui a Política Nacional de Atenção as Urgências, a ser implantada em todas as unidades federadas, respeitadas as competências das três esferas de gestão. Brasília, DF.

Ministério da Saúde. (2002). Portaria MS 2048/02, de 05 de novembro de 2002. Aprova o regulamento técnico dos sistemas estaduais de urgência e emergência. Brasília, DF

Ministério da Saúde. (2003). Portaria MS 1864/03, de 29 de setembro de 2003. Institui o componente préhospitalar móvel da Política Nacional de Atenção às Urgências, por intermédio da implantação do Serviço de Atendimento Móvel de Urgências em municípios e regiões de todo o território brasileiro: SAMU 192. Brasília, DF.

Grossi, L. M., Pisa, I. T., \& Marin, H.de F. (2015). Tecnologia da Informação e Comunicação na Auditoria em Enfermagem. J. Health Inform. 7(1): 30-4

Halfoun, V. L. R. C, Aguiar, O. B. de, \& Mattos, D. S. (2008). Construção de um Instrumento para Avaliação de Satisfação da Atenção Básica nos Centros Municipais de Saúde do Rio de Janeiro, 2008.

Junqueira, L. A. P. (1997). Novas formas de gestão na saúde: descentralização e intersetorialidade. Revista Saúde e Sociedade. 6(2):31-46.

Lobiondo-wood, G., \& Haber, J. (2001). Pesquisa em Enfermagem: Métodos, avaliação crítica e utilização. (4a ed.), Guanabara-Koogan.

Lopes, S. L. B., \& Fernandes, R. J. (1999). Uma breve revisão sobre o atendimento médico pré-hospitalar. Medicina. (32). $381-387$.

Lynn, M. V. (1986). Determinacionandqualificacionof contente validaty. Nurs. Res. 35(6), 382-5.

Malvestio. M.A. A, \& Souza. R. M. C. (2002). Suporte avançado à vida: atendimento a vítimas de acidentes de trânsito. Revista Saúde Pública. 36(5).

Martins, P. P. (2004). Atendimento pré-hospitalar - Atribuição e responsabilidade de quem? Uma reflexão crítica a partir do serviço do corpo de bombeiros e das políticas de saúde "para" o Brasil à luz da filosofia das práxis. 2004. Dissertação (Mestrado em Enfermagem) - Curso de Pós-Graduação em Enfermagem, Universidade Federal de Santa Catarina. Florianópolis, 264f.

Martins, P. P. S, \& Prado, M. L. (2003). Enfermagem e Serviços de Atendimento Pré-Hospitalar: descaminhos e perspectivas. Revista Brasileira de Enfermagem, Brasília, 71-75.

Polit, D. F., \& Beck, C. T. (2011). Fundamentos de pesquisa em Enfermagem: avaliação de evidências para a prática de Enfermagem. (7a ed.), Ed. Artmed, 2011 .

Ramos, F. R. S. (2002). Ética e cuidado de enfermagem: o sentido desta relação. In:Prado, M.L., Gelbcke, F.L. (Org) Fundamentos de Enfermagem. Cidade Futura.

Ramos, V. O., \& Sanna, M. C. (2005). A insersão da enfermeira no artendimentopréhospitalar: histórico e perspectivas atuais. Revista Brasileira de Enfermagem, 58(3),355-360.

Rocha, P. K. (2000). Assistência de Enfermagem em serviço de emergência préhospitalar e remoção aeromédica. Monografia (Graduação em Enfermagem). Centro de Ciências da Saúde. Universidade Federal de Santa Catarina. Florianópolis.

Sauro, J. (2009). Measuring Usability With The System Usability Scale (SUS).

Sordi, J. O.de, Meireles, M. A. (2010). Extração de maior valor dos sistemas de informação voltados para as redes: importância do domínio semântico dos protocolos de comunicação pelos atores. Perspectivas em Ciências da informação, 15(1), 198-2019.

Stetler C. B, Morsi D, Rucki S, Broughton S, Corrigan B, Fitzgerald J, et al. (1998) Utilization focused integrative reviews in a nursing service. ApplNurs Res. Nov, 11(4):195-206.

Stetler, C. B. et al. (1998). Evidence-based practice and the role of nursing leadership. JONA, 28(7-80), 45-53.

Torquato, G. (2004). tratado de comunicação organizacional e política. São Paulo: Pioneira Thomson.

Whittemore, R. (2005). Combining evidence in nursing research: methods and implications. NURS RES. 54(1):56-62. 